\title{
The refractory and supernormal periods of the human median nerve
}

\author{
R. W. GILLIATT AND R. G. WILLISON ${ }^{1}$ \\ From the Institute of Clinical Research, the Middlesex Hospital Medical School, and the Department \\ of Applied Electrophysiology, the National Hospital, Queen Square, London
}

While the excitability changes which follow a propagated nerve impulse have been the subject of numerous studies in animals, there have been few references to this subject in man. An attempt to study the refractory period of the human ulnar nerve was made by Wagman and Flick (1951), but as recordings were made from the hypothenar muscles rather than from the nerve itself, the results are difficult to interpret. Krnjević, Kilpatrick, and Aungle (1955) applied pairs of shocks to the ulnar nerve at the wrist, and investigated the least interval at which a response to the second shock could be recorded from the nerve at the elbow; only two subjects were examined and no estimate of the relative refractory period was made. Brown (1960) also used stimulation of the ulnar nerve at the wrist with recording at the elbow in four subjects, and noted that the recovery of normal responsiveness was followed by transient supernormality.

In the present work we have studied the refractory and supernormal periods of the human median nerve with stimulation at the wrist, action potentials being recorded from the nerve above the elbow by a technique similar to that originally described by Dawson and Scott (1949). A brief preliminary account of this work has been published elsewhere (Gilliatt and Willison, 1962).

\section{METHODS}

Four healthy subjects were used, their ages ranging from 20 to 40 years. Most of the experiments were carried out on two subjects (R.W.G. and R.G.W.) but the main results were confirmed in the other two subjects as well.

Before each experiment the subject sat with both arms in hot water to above the elbows for five or $\mathbf{1 0}$ minutes. He then lay covered with blankets on a couch, with the arm under examination wrapped in several layers of cotton wool. When these precautions were taken skin temperature, which was measured by a thermistor close to the stimulating cathode, remained above $35^{\circ} \mathrm{C}$. throughout experiments lasting up to one hour; no

'Clinical research fellow, M.R.C. experiments are included in the present series in which skin temperature fell below $35^{\circ} \mathrm{C}$.

Two stimuli of independently variable intensity were delivered through a single cathode over the median nerve at the wrist. The stimulus interval could be varied in $0.1 \mathrm{msec}$. steps from 0 to $11.0 \mathrm{msec}$. and in $1 \mathrm{msec}$. steps for intervals longer than this. Each stimulus was a condenser discharge with a rapid rise-time, the decay having a time constant of 60,100 , or $160 \mu \mathrm{sec}$. Voltage was continuously variable up to $350 \mathrm{~V}$. In most of the experiments a time constant of $160 \mu \mathrm{sec}$. was used for both shocks but when small changes in nerve threshold were to be studied, for example, in plotting the supernormal period, a shorter time constant was used for the

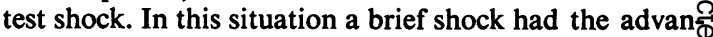
tage that a larger voltage range could be used when the physiological change in nerve threshold was small. Botti stimuli were delivered through a single isolating transe former (ratio $1: 1$ ) the output impedance being less than $1 \mathrm{kilohm}$. To allow mixing of stimuli from two thyratrons $\overrightarrow{.}$ silicon diodes were placed in the primary circuit of the \& transformer. A silicon diode was also placed in series with the subject to prevent oscillation due to capacitance and inductance in the secondary circuit of the transformer. In a few experiments in which shocks were to be applied to different points on the skin two transformers were used.

The stimulating cathode was a circular pad $1.5 \mathrm{~cm}$. in diameter. In most experiments the anode was a metal plate on the back of the wrist but in a few experiments an anode over the thenar muscles was preferred. These positions for the anode were chosen for convenience and did not affect the experimental results.

For recording nerve action potentials a conventional R-C coupled amplifier was used. When photographic records were made the stimuli were usually set to repeat at intervals of 1 second and 50 faint traces were superimposed. When, however, records were being taken during brief periods of ischaemia, so that the condition of the nerve was changing during the experiment, a 50-second recording period was too long for each observation and in these experiments only 40 traces were superimposed, the repetition rate being increased to 2 per second. There were only a few experiments in which such strong shocks were used that subjects could not tolerate repeated stimuli. On these occasions single frames were photographed (e.g., Fig. 2).

Surface recording electrodes of the type originally $N$ described by Dawson and Scott (1949) were used. At 136 


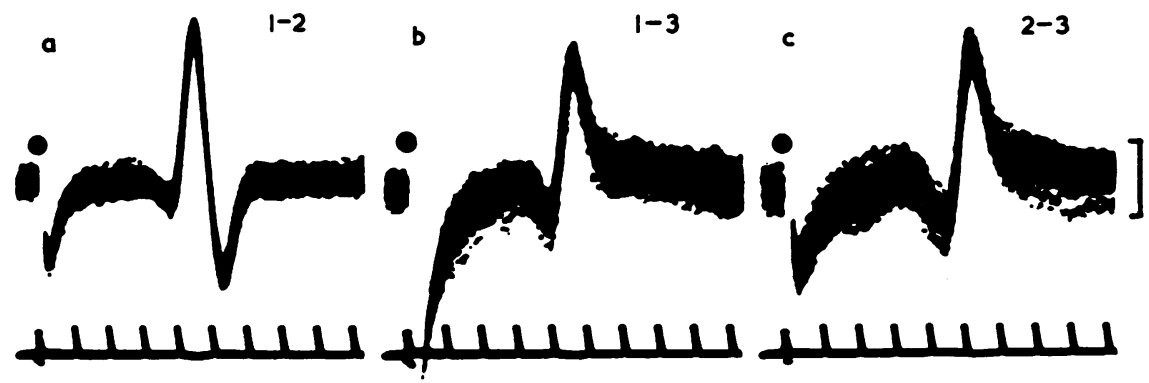

FIG. 1. Subject R.W.G. Records from the median nerve above the

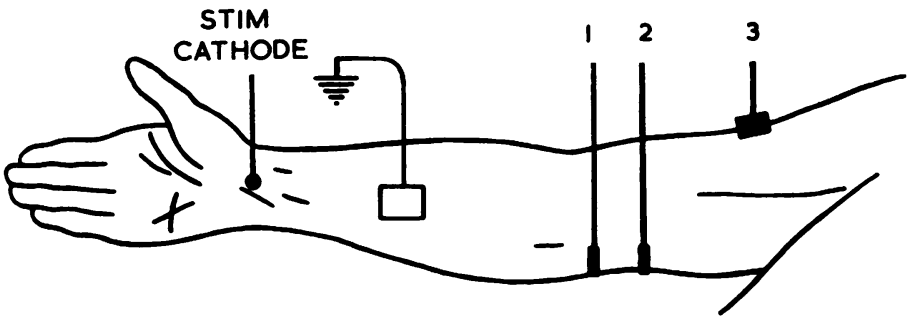
elbow to show the effect of different electrode positions on action potential waveform. Stimulus to the nerve at the wrist unchanged throughout. Recordings are from electrodes 1 and 2 in $a, 1$ and 3 in $b, 2$ and 3 in c. Stimulus at mark. Calibration $20 \mu \mathrm{V}$. Time scale in msec. Fifty faint traces superimposed.

first, two electrodes placed $4 \mathrm{~cm}$. apart along the course of the nerve above the elbow were tried. Symmetrical pick-up electrodes placed a few centimetres apart in this way have the advantage that random muscle action potentials in other parts of the limb have little effect on the trace so that a steady baseline is easily obtained for superimposed records. A disadvantage is the triphasic waveform of the recorded potential, which raised particular difficulty in the present experiments since we were attempting to record one action potential following closely upon another. In order to simplify waveform a small exploring electrode over the median nerve was therefore tried with a remote electrode over the deltoid insertion. In the tracings shown in Fig. 1 single shocks were delivered to the median nerve at the wrist at intervals of 1 sec., the stimulus being unchanged throughout. Figure 1a shows 50 superimposed action potentials recorded through two electrodes $4 \mathrm{~cm}$. apart over the course of the median nerve. Figures $1 \mathrm{~b}$ and $1 \mathrm{c}$ show the action potential recorded between each electrode of the pair and the remote electrode, 50 sweeps being superimposed in each case. The slightly thicker baseline in the superimposed records in Figs. 1b and 1c may be noted. This indicates background muscle activity, probably in biceps, which is eliminated by the position of the recording electrodes in Fig. 1a but not in Figs. 1b and 1c. Random muscle activity of this sort did not prove a serious problem in trained subjects and the arrangement shown in Fig. 1b was that finally adopted for the present experiments.

In some experiments the effects of ischaemia were studied; to produce this a sphygmomanometer cuff was rapidly inflated round the upper arm to 200 or $220 \mathrm{~mm}$. $\mathrm{Hg}$ and maintained at this pressure for 12 minutes. Provided that the subject had been thoroughly warmed before the experiment and provided that the arm was wrapped in cotton wool in the usual way, skin temperature in the region of the stimulating cathode did not fall by more than $0.5^{\circ} \mathrm{C}$. during ischaemia. In these experiments the position of the stimulating electrodes at the wrist was similar to that described above. For recording during ischaemia, however, the active electrode was placed over the median nerve in the antecubital fossa and the remote electrode moved down from the region of the deltoid insertion to the lateral side of the elbow joint. This made it possible to inflate a cuff $15 \mathrm{~cm}$. wide round the upper arm without any displacement of recording electrodes.

\section{RESULTS}

CHANGES IN EXCITABILITY The least interval between two stimuli at which it was possible to record a propagated response to the second stimulus of the pair was determined in the four subjects. When a single shock is delivered to the median nerve at the wrist, the action potential recorded at the elbow reaches maximal amplitude at a stimulus voltage approximately three times the threshold value; for the determination of the least interval, stimulus intensities of between four and six times threshold were used. Stronger shocks were too painful to be tolerated by the subjects. When two supramaximal stimuli were delivered at an interval of $0.5 \mathrm{msec}$. or less there was no recordable response to the second shock in any subject. The stimulus interval was then increased in 0.1 msec. steps; a second response was seen in two subjects at a stimulus interval of 0.6 msec. and in the other two subjects at an interval of 0.7 msec. Illustrative records from one subject are shown in Fig. 2.

For the determination of the relative refractory period the first stimulus (S1) remained supramaximal 

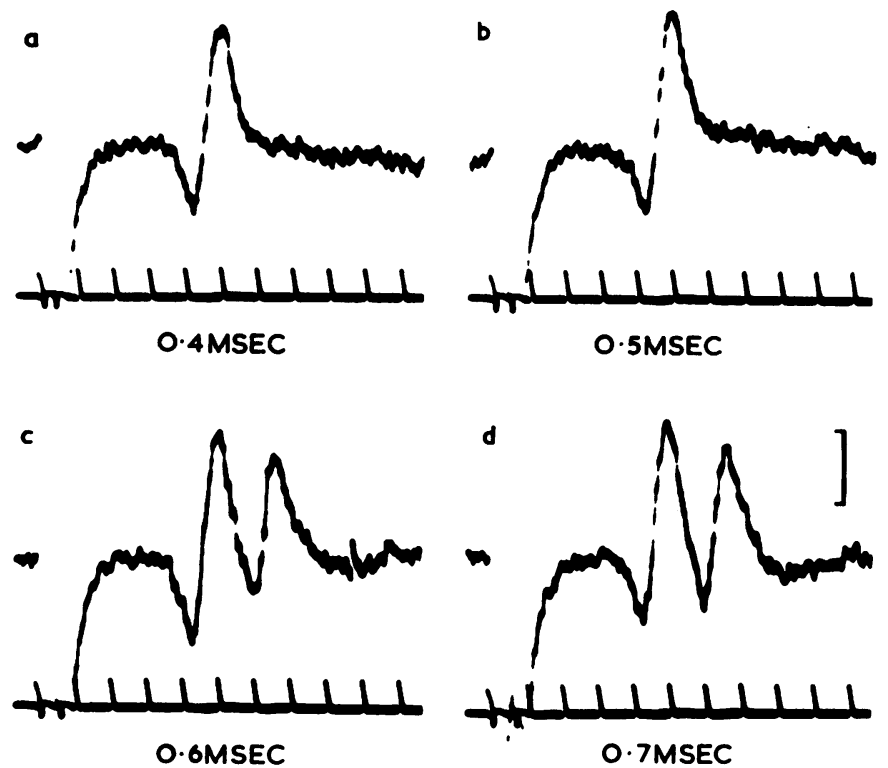

FIG. 2. Subject R.G.W. Records from median nerve to show the effect of two supramaximal shocks. Electrode positions as in Figure 1b. Stimulus interval increased successfully from $0-4 \mathrm{msec}$. in (a) 0.7 msec. in (d). In this subject no response to the second shock was seen at intervals of less than 0.6 msec. Calibration $20 \mu \mathrm{V}$. Time scale in msec. and the voltage of the second stimulus (S2) was adjusted to give the smallest response that could be recognized with certainty on inspection of the trace (3-5 $\mu \mathrm{V})$. The voltage of $\mathrm{S} 2$ required to produce a minimal response fell as the interval between stimuli was increased, the resting value being reached after 2.5 to $3.5 \mathrm{msec}$. Results for the four subjects are shown graphically in Fig. 3, the voltage of $\mathbf{S 2}$ being expressed as a percentage of the resting figure. In all four subjects the recovery of normal excitability was followed by a period of supernormality in which the nerve threshold fell slightly below the resting value. This is shown in Fig. 4 from which it can be seen that the threshold fell by as much as 10 to $12 \%$ in three subjects; in the other subject there was a change of only $4 \%$. Supernormal excitability was maximal 5 to $8 \mathrm{msec}$. after $\mathrm{S} 1$; thereafter it declined, the threshold returning to its resting value within 10 to $20 \mathrm{msec}$.

To obtain each of the points plotted in Fig. 4 the voltage of S2 was slowly increased until a minimal response was seen on the trace; the stimulating voltage was then noted and the procedure repeated for a different stimulus interval. With the naked eye it was not possible to detect action potentials of less than 3 to $5 \mu \mathrm{V}$ in amplitude, and in order to supplement visual examination of the trace superimposed records were photographed in two subjects. In this case a fixed stimulus interval of $6.0 \mathrm{msec}$. was used and the response to $S 2$ alone and to $S 2$ preceded by S1 recorded for different voltages of $\mathbf{S 2}$; S1 was supramaximal throughout.
The results of one such experiment are shown in Figure 5. By superimposition of 50 faint traces at increased amplification, action potentials approximately $0.5 \mu \mathrm{V}$. in amplitude could be distinguished from background noise. It can be seen from Fig. 5 that for $\mathrm{S} 2$ alone a response of approximately $0.5 \mu \mathrm{V}$ was obtained at a stimulus voltage of $83 \mathrm{~V}$; when $\mathrm{S} 2$ was preceded by $\mathrm{S} 1$ a similar response was obtained with an S2 voltage of $73 \mathrm{~V}$. This represents a fall in threshold of $12 \%$. A response of $3.5 \mu \mathrm{V}$ was obtained for $\mathrm{S} 2$ alone at $98 \mathrm{~V}$ whereas a response of the same size was obtained with $\mathrm{S} 2$ at $86 \mathrm{~V}$ when it was preceded by S1. Thus the fall in nerve threshold was again $12 \%$. This confirms the validity of the threshold changes obtained by visual inspection of the trace in the experiments shown in Fig. 4.

In one subject there was some evidence of subnormal excitability following the supernormal period (A.H. in Fig. 4) but this was not investigated further. The design of the present experiments was not entirely suitable for studying subnormality for the following reason. Using a supramaximal S1 shock it seemed possible that with stimulus intervals of more than 15 to $20 \mathrm{msec}$. the thenar muscle twitch caused by $\mathrm{S} 1$ might displace the stimulating cathode at the wrist sufficiently to produce an apparent alteration in threshold to S2. Displacement of the cathode would not have to be large in order to produce an apparent change in nerve threshold of 3 to $5 \%$ and for this reason it seemed that a differently designed experiment (perhaps using a purely sensory nerve) would be required for the investigation of excitability 


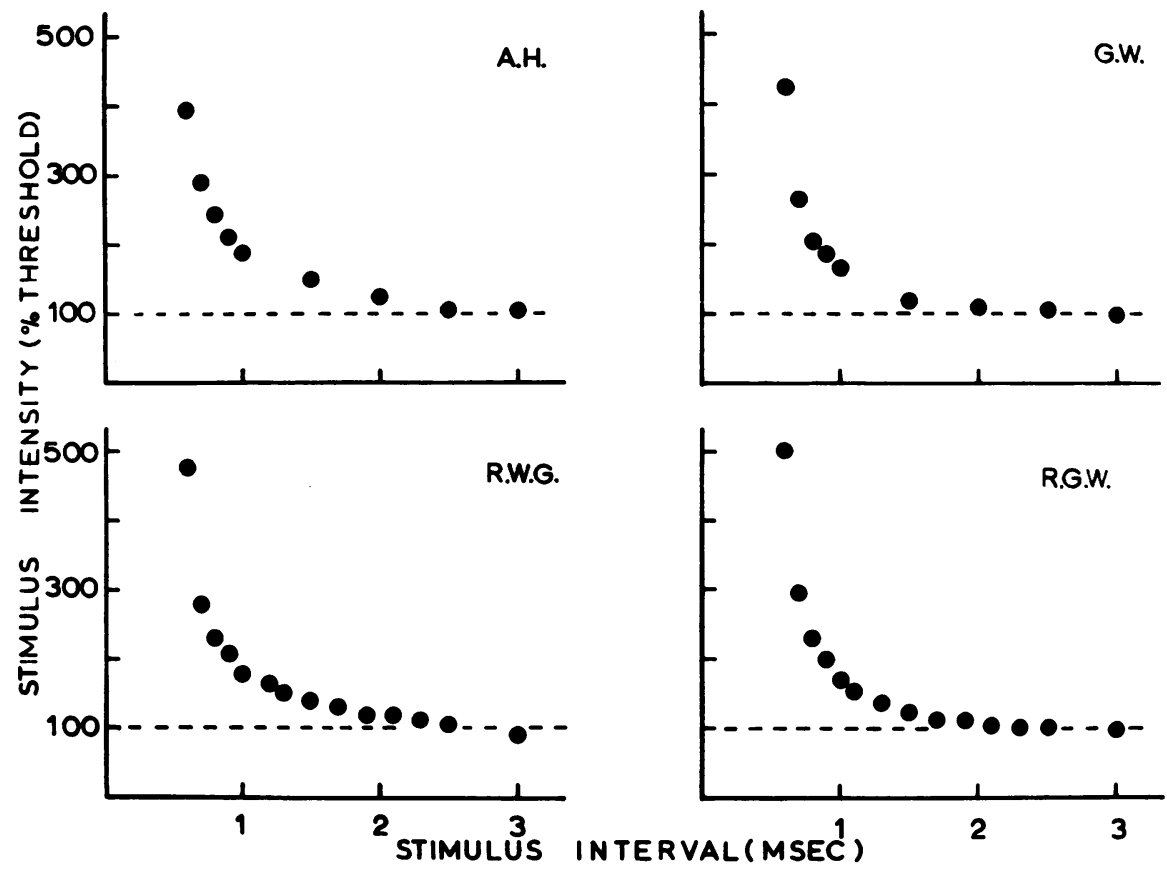

FIG. 3. Recovery of excitability in four subjects. Ordinates: stimulus intensity expressed as percentage of resting threshold. Abscissae: stimulus interval in msec. Electrode positions as in Figure $1 b$.

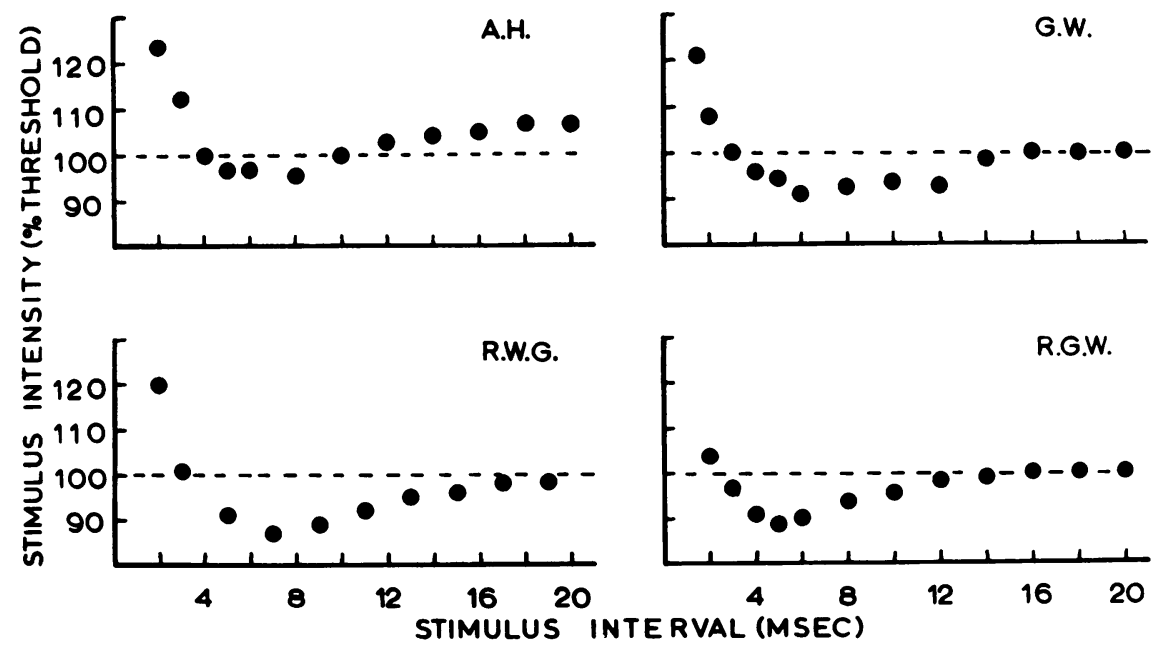

FIG. 4. Supernormal excitability in four subjects. Presentation as in Fig. 3. Recovery of normal excitability is followed by transient fall of nerve threshold below resting value. 


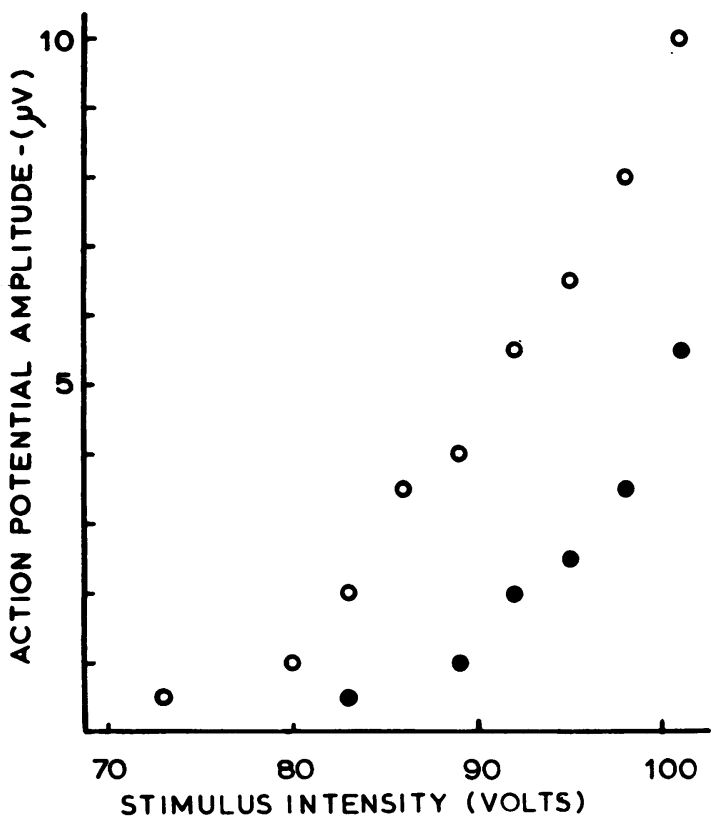

FIG. 5. Subject R.G.W. To show effect of supernormal excitability on response height for stimulus intensities just above threshold value. Electrode positions as in Figure $1 b$. For each stimulating voltage used, action potential amplitude was recorded both when stimulus was delivered alone (closed circles) and when it was preceded by a maximal shock delivered 6 msec. earlier (open circles). changes taking place more than 15 to $20 \mathrm{msec}$. after S1.

EXCITABILITY CHANGES IN DIFFERENT FIBRES OF THE NERVE TRUNK While 2.5 to $3.5 \mathrm{msec}$ may be regarded as the end of the relative refractory period for the most excitable fibres in the median nerve, there is no doubt that some fibres have an appreciably longer refractory period. This is shown by the experiment illustrated in Fig. 6a. In this experiment a supramaximal shock $S 1$ was followed after an interval of $3.0 \mathrm{msec}$. by a second shock $\mathrm{S} 2$, the voltage of $\mathbf{S} 2$ being increased in successive steps from near threshold to maximal. For each level of S2, superimposed records were made of the action potential at the elbow, both when S2 was delivered alone and when it was preceded by S1. When S2 was near threshold only the most excitable fibres were stimulated, and it can be seen from Fig. 6a that the recorded action potential was slightly larger when $\mathbf{S} 2$ was preceded by $\mathbf{S 1}$ than when S2 was delivered alone. This suggests that some of the fibres were already showing supernormal excitability $3.0 \mathrm{msec}$. after S1. When, however, the strength of $\mathbf{S 2}$ was near maximal the resulting actiorn potential was always smaller when $\mathbf{S} 2$ was preceded by $\mathbf{S} 1$ than when $\mathbf{S} 2$ was delivered alone, indicating that some fibres in the nerve were still refractory at this interval.

In contrast to the result described above, it could be shown that by $6.0 \mathrm{msec}$. the remaining fibres con

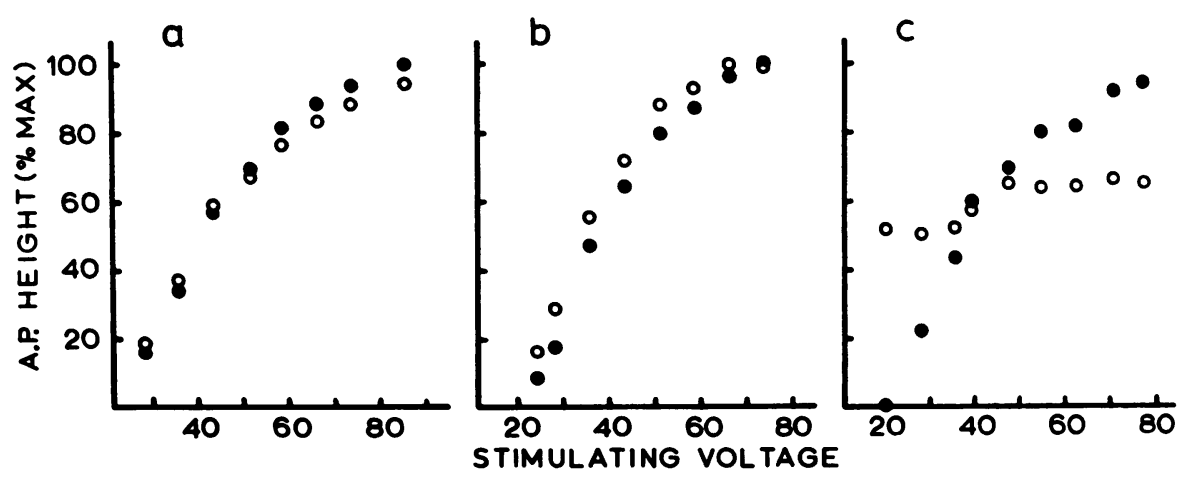

FIG. 6. Subject R.W.G.

a To show the effect of a preceding shock on the response to a stimulus of increasing intensity. Electrode positions as in Figure $1 b$. For each stimulating voltage used, action potential amplitude was recorded both when stimulus was delivered alone (closed circles) and when it was preceded by a maximal shock delivered 3 msec. earlier (open circles).

$b$ Experiment shown in Fig. 6 a repeated with shock interval of 6 msec.

c First stimulus increased in voltage from threshold to near maximal, action potential amplitude being shown by closed circles. Electrode positions as in Figure $1 b$. For each stimulating voltage used a second stimulus was delivered 6 msec. later, its intensity being unchanged throughout. Amplitude of response to second stimulus (open circles) did not increase until first stimulus was stronger than second. 
tributing to the main deflection of the action potential had recovered from refractoriness and showed supernormality. This is illustrated by Fig. $6 \mathrm{~b}$, the experimental arrangement being identical with that used in Fig. 6a except that the stimulus interval was $6.0 \mathrm{msec}$. instead of $3.0 \mathrm{msec}$. It can be seen from Fig. $6 \mathrm{~b}$ that the amplitude of the response to $S 2$ was always larger when this was preceded by $S 1$ than when S2 was delivered alone, except for the single point on the curve when $\mathbf{S} 2$ itself produced a maximal response.

In order to investigate the cause of supernormal excitability a third type of experiment was carried out which is illustrated in Fig. 6c. Two shocks were again delivered to the nerve at the wrist separated by an interval of $6.0 \mathrm{msec}$. In this case the strength of $\mathbf{S 1}$ was gradually increased from below threshold to near maximal, the strength of S2 remaining constant throughout the experiment at a level sufficient to produce an action potential of approximately half maximal amplitude. The result of this procedure is shown in Fig. $6 \mathrm{c}$, in which the response to $S 1$ is shown by closed circles and the response to $\mathbf{S 2}$ by open circles; it is clear that an enhanced response to $\mathrm{S} 2$ was only seen when the response to S1 was greater than that to S2. This indicates that subliminal excitation by $\mathrm{S} 1$ was not effective in producing a change in threshold to S2. Once, however, S1 was stronger than S2, supernormal excitability could be demonstrated. This result indicates that supernormality only occurred in fibres which had already responded to the first shock of the pair.

From animal experiments it has long been known that refractoriness and supernormality can be demonstrated in nerve not only when both shocks are delivered through the same cathode but also when the second shock is delivered to the nerve at a distance (Adrian and Lucas, 1912). This observation is confirmed by the experiment illustrated in Fig. 7. In this case two stimulating cathodes were placed $3 \mathrm{~cm}$. apart over the course of the median nerve at the wrist, the anode being a metal plate on the dorsum of the wrist. A supramaximal shock S1 could be delivered through either cathode whereas the second shock S2 was always delivered through the proximal cathode. Action potentials were recorded from the nerve above the elbow and the strength of $\mathbf{S} 2$ was adjusted to produce an action potential of slightly less than half maximal amplitude. The open circles in Fig. 7 show the amplitude of the action potential produced by 22 when preceded by $\mathrm{S} 1$ at intervals of 2.5 to $5.0 \mathrm{msec}$., both shocks being delivered through the proximal cathode. It can be seen that at an interval of $2.5 \mathrm{msec}$. some fibres were still refractory to $S 2$, the amplitude of the resulting action potential being less than when $S 2$ was
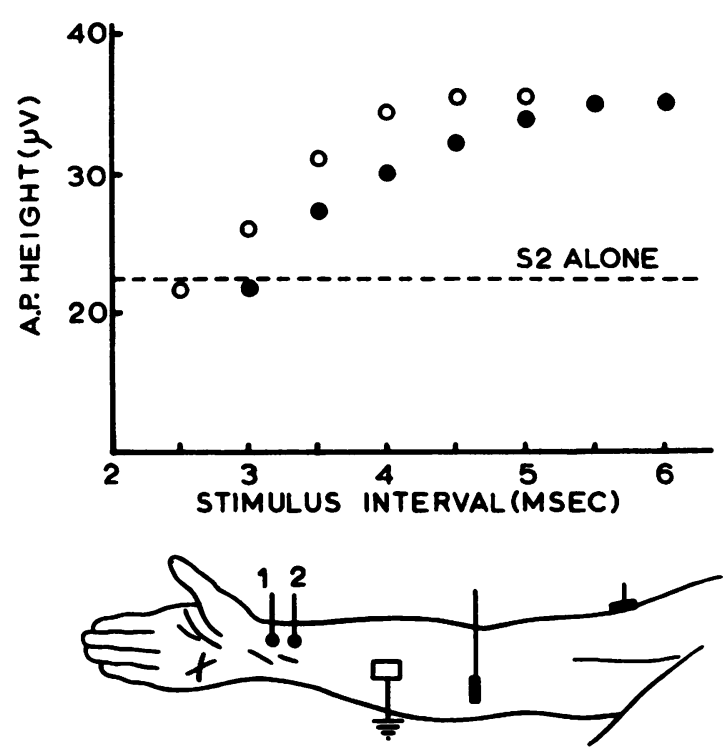

FIG. 7. Subject R.W.G. A weak shock $S 2$ preceded by a maximal shock $S 1$. S2 delivered through cathode 2 at wrist, S1 delivered through either cathode 1 or 2 . Open circles denote amplitude of action potentials recorded above elbow in response to $S 2$ when both $S 1$ and $S 2$ were delivered through cathode 2. Closed circles denote amplitude of response when S1 was delivered through cathode 1. Stimulus interval varied from 2.5 to 6 msec. Amplitude of responses to $S 2$ alone shown by broken line.

delivered alone. At longer stimulus intervals the response to $\mathbf{S} 2$ was greater when it was preceded by S1 than when it was delivered alone, the maximal increase in action potential amplitude being seen at 4.5 to $5.0 \mathrm{msec}$.

The closed circles in Fig. 7 show the amplitude of the action potential produced by $S 2$ delivered through the proximal cathode but preceded by S1 delivered through the distal cathode. It can be seen that the result was essentially similar to that obtained when both $S 1$ and S2 were fed through the same cathode, except that the onset of supernormality was delayed by an interval of $0.5 \mathrm{msec}$., which may be attributed to the conduction time of the S1 volley from the distal to the proximal cathode.

This result confirms the previous findings of Adrian and Lucas (1912) and of subsequent workers. It is clear that the changes in excitability observed after a single shock to the median nerve in our experiments were not due to the local effects of stimulating current at the site of excitation, since they occurred in a segment of nerve at a distance from this point provided that the fibres concerned had conducted a propagated action potential. 

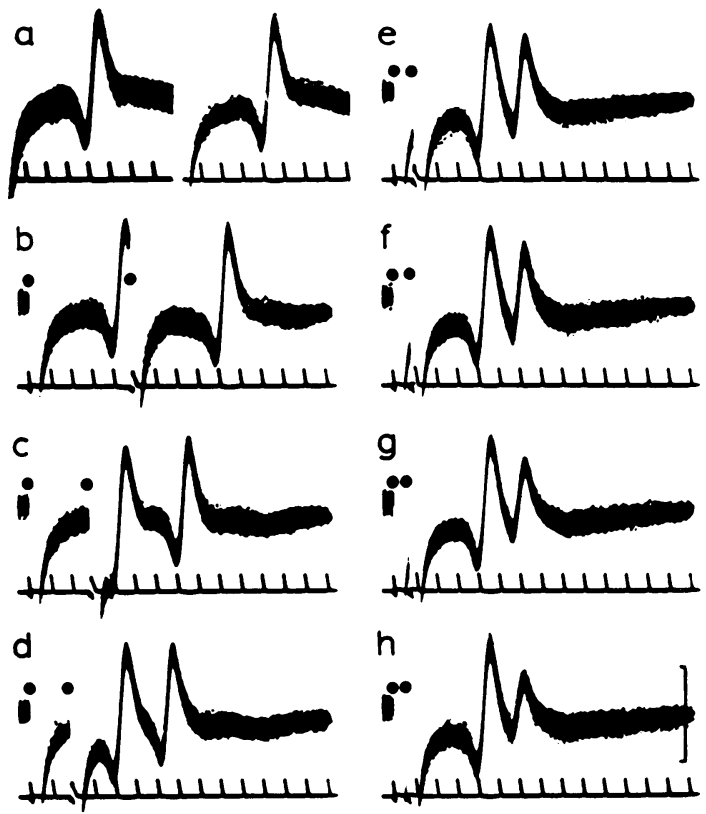

FIG. 8. Subject R.G.W. Records from median nerve above the elbow to show action potentials recorded in response to two maximal stimuli at the wrist. Stimuli delivered separately (a) or successively at decreasing intervals from $5 \mathrm{msec}$. to $0.7 \mathrm{msec}$. $(b-h)$. Stimulus at mark in each case. Calibration $40 \mu \mathrm{V}$. Time scale in msec. Fifty faint traces superimposed.

CHANGES IN CONDUCTION VELOCITY It was first shown by Forbes, Ray, and Griffith (1923) that conduction velocity is reduced when an impulse is travelling in nerve which is recovering from the passage of a previous impulse. This is clearly shown by Fig. 8 ; in this experiment two maximal stimuli were delivered to the median nerve at the wrist at intervals of $5,3,2,1,0.9,0.8$, and $0.7 \mathrm{msec}$. Figure 8 shows the action potentials recorded from the nerve at the elbow. The action potentials recorded when the two stimuli were delivered separately are shown in Fig. 8a. For stimulus intervals of 5.0 and 3.0 msec. (Fig. $8 \mathrm{~b}$ and c) the response interval (measured from either the foot or the peak of the main deflection of the first action potential to a comparable point on the second) was equal to the stimulus interval. When, however, the second action potential was travelling in nerve which was partially refractory (Fig. 8d to h) its velocity was slowed, resulting in a response interval which did not shorten to less than $1.6 \mathrm{msec}$, even when the stimuli were $0.7 \mathrm{msec}$. apart (Fig. 8h).

In order to determine the conduction velocity of the first and second action potentials, experiments were carried out in two subjects in whom action potentials were recorded from the median nerve both at the level of the elbow and in the axilla. In the experiment illustrated in Fig. 9, two maximal stimuli were delivered to the median nerve at the wrist at an interval of $0.8 \mathrm{msec}$, the action potentials recorded from the nerve at the elbow and axilla being displayed on the lower and upper traces of the oscilloscope. The distance between the elbow and axillary electrodes was $20 \mathrm{~cm}$. from which conduction velocity is calculated to be $69 \mathrm{~m}$./sec. for the first action potential and $60.5 \mathrm{~m}$./sec. for the second. Corresponding figures for a similar experiment on another subject were 65.5 and $61.5 \mathrm{~m}$. $/ \mathrm{sec}$.

The tracings shown in Fig. 9 were taken from an experiment in which the interval between two stimuli was shortened in successive records from 5.0 to 0.8 msec. Results of the full experiment are shown graphically in Fig. 10. This figure confirms the point made earlier that the response interval and the stimulus interval are identical when the two stimuli are separated by more than the refractory period, but that with stimuli which are closer together than this the response interval fails to shorten due to the reduced conduction velocity of the second action potential. This supports the observation of Gasser and Erlanger (1925) that recovery of velocity serves to indicate the end of the refractory period ase accurately as the recovery of excitability.

From animal experiments it is known that when two impulses are initiated at a brief interval thee velocity of the second shows its greatest reduction close to the site of stimulation, and it is interesting? that in our experiment the velocity of the second action potential was still reduced more than 30 $\mathrm{cm}$. from the site of stimulation.

EFFECTS OF ISCHAEMIA The effects of ischaemia on refractoriness and supernormality were investigated in two subjects. In the experiment illustrated in Fig. 11 two identical shocks were delivered to the median nerve at the wrist at an interval of $2.0 \mathrm{msec}$. Action potentials were recorded from the nerve at the elbow, 40 faint traces being superimposed in each record. Stimulus intensity was adjusted to give an action potential at the elbow of approximately half maximal amplitude. It can be seen from the upper trace in Fig. 11 that many fibres in the nerve trunk were still refractory to the second shock when it was delivered $2.0 \mathrm{msec}$. after the first. Thus even before ischaemia the amplitude of the second action potential was only $59 \%$ of the first. A cuff was then inflated round the upper arm to above arterial pressure and stimulation repeated at intervals during ischaemia, stimulus intensity being unchanged throughout. It can be seen from the lower trace in Fig. 11 that after 11 minutes of ischaemia the second 

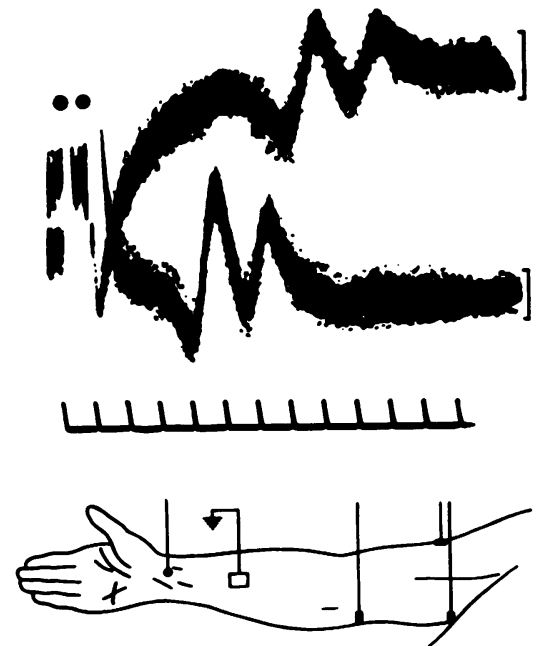

FIG. 9

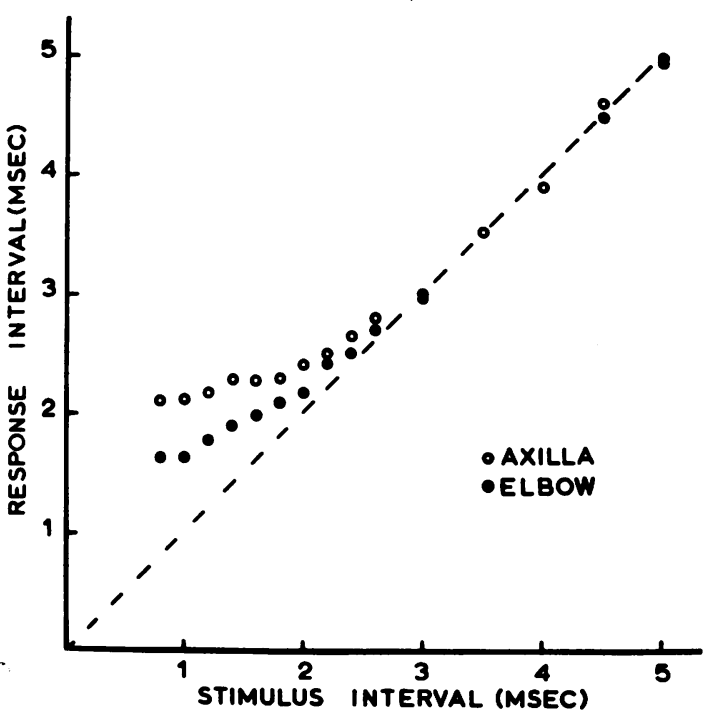

FIG. 10

FIG. 9. Subject R.G.W. Action potentials recorded from the median nerve just above the elbow (lower trace) and in the axilla (upper trace) when two maximal shocks delivered to the nerve at the wrist at an interval of $0.8 \mathrm{msec}$. Calibration $10 \mu \mathrm{V}$. Time scale in msec. Fifty faint traces superimposed.

FIG. 10. Complete results of the experiment illustrated in Fig. 9. Response interval (measured from the onset of the main deflection of the action potential in each case) plotted against the stimulus interval to show that the second action potential lags behind the first when travelling in partially refractory nerve. action potential had virtually disappeared, the first potential being delayed but only slightly reduced in amplitude. From this experiment it is clear that the refractory period is markedly affected by short periods of ischaemia.

The effect of ischaemia on supernormal excitability is illustrated in Fig. 12. The positions of the stimulating and recording electrodes and of the sphygmomanometer cuff were similar to those shown

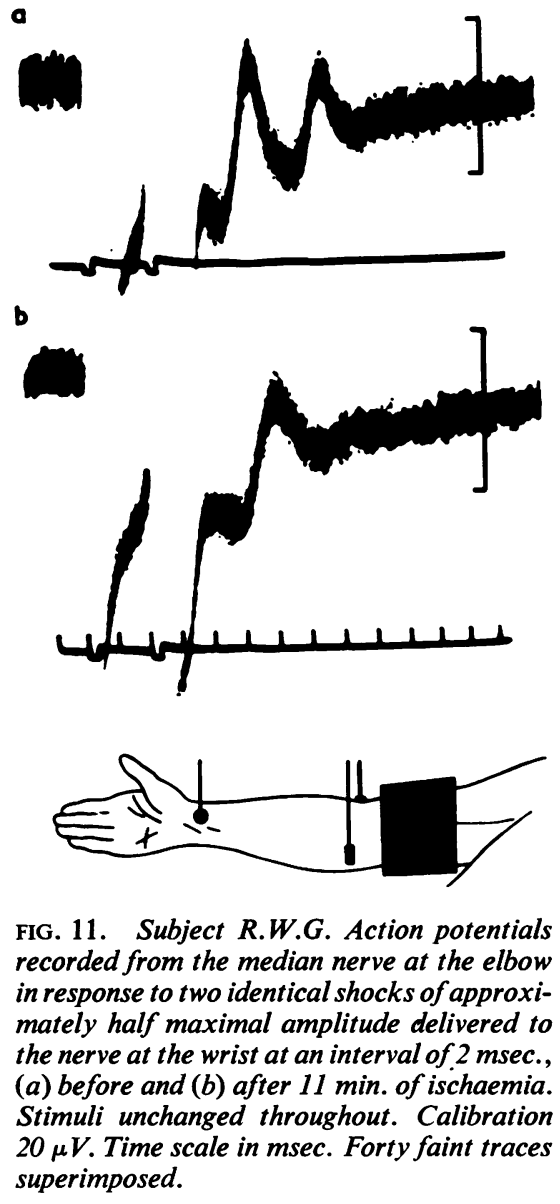

in Fig. 11 but on this occasion a maximal shock S1 was used, followed by a weak shock S2, the latter being sufficient (when delivered alone) to give an action potential of between a third and a half maximal amplitude. With a stimulus interval of $5.0 \mathrm{msec}$. it can be seen that before ischaemia the action potential produced by $\mathbf{S} 2$ was considerably larger when it was preceded by S1 (Fig. 12b) than when it was delivered alone (Fig. 12a), the increase in action potential amplitude being approximately 


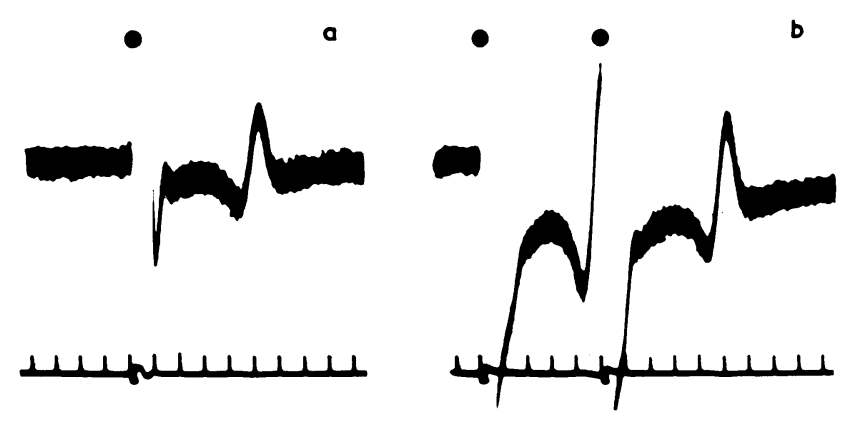

FIG. 12. Subject R.W.G. Effect of ischaemia on supernormal excitability. Electrode positions as in Fig. 11; S1 maximal, S2 less than half maximal intensity. Stimulus interval 5 msec. Records $(a)$ and $(b)$ taken before, and

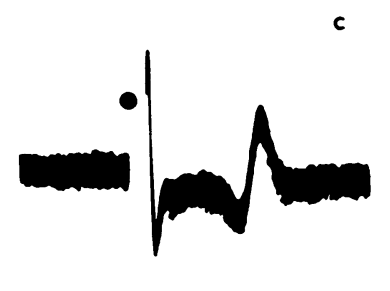

$d$ $(c)$ and $(d)$ after ischaemia for six minutes. Stimuli unchanged throughout. Calibration $20 \mu \mathrm{V}$. Time scale in msec. Forty faint traces superimposed.
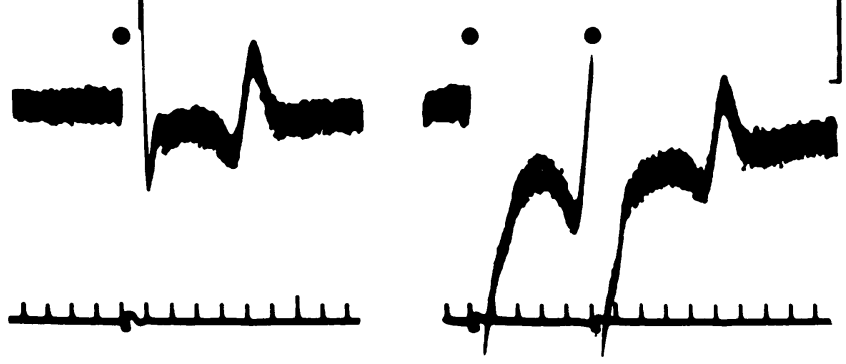

$40 \%$. After six minutes of ischaemia, however, no supernormality could be demonstrated, the response to $\mathrm{S} 2$ preceded by $\mathrm{S} 1$ (Fig. 12d) being similar to that obtained when $\mathbf{S} 2$ was delivered alone (Fig. 12c). Loss of supernormality during ischaemia was confirmed for stimulus intervals of 6,7 , and $10 \mathrm{msec}$. in different experiments in two subjects.

To study the duration of the refractory period during ischaemia, four separate experiments were carried out in each of two subjects, using fixed stimulus intervals of $2,3,4$, and $5 \mathrm{msec}$. To avoid any possible cumulative effect of ischaemia, experiments were carried out at intervals of not less than five days. The experimental arrangement was similar to that described previously, a maximal shock S1 being followed by a weak shock $\mathrm{S} 2$ as in the experiment shown in Fig. 12. Superimposed records of the response to $\mathbf{S} 2$ when preceded by $S 1$ and of the response to $\mathrm{S} 2$ alone were made successively every two minutes both before and during a 12-minute period of ischaemia, and Fig. 13 shows the results of four experiments in one subject. For each experiment the amplitude of the response to S2 alone before ischaemia has been given the value of 100 and all other values are plotted as percentages of this. Considering first the effect of ischaemia on this response alone, it can be seen that in all four experiments there was a substantial increase in amplitude during the first few minutes of ischaemia, indicating a transient fall in nerve threshold. Thi is comparable to the lowering of threshold describe by Kugelberg (1944) in motor fibres during the earlw stages of ischaemia. Thereafter the nerve threshold $\vec{\theta}$ appeared to rise progressively, the response being reduced to about $60 \%$ of its initial size after 12 minutes.

In Fig. 13 responses to $\mathrm{S} 2$ when this was preceded by $\mathrm{S} 1$ are shown as open circles. Action potential amplitude in each case is plotted as a percentage of that recorded for $\mathbf{S} 2$ alone before ischaemia. In Fig. 13a the stimulus interval was $2.0 \mathrm{msec}$. and it can be seen that before ischaemia the amplitude of the response to $\mathrm{S} 2$ was reduced by $50 \%$ when $\mathrm{S} 2$ was preceded by $\mathrm{S} 1$. During ischaemia the response decreased still further in size and disappeared altogether by the end of 12 minutes. In Fig. 13b the stimulus interval was $3.0 \mathrm{msec}$. and before ischaemia the response to $\mathbf{S} 2$ was slightly increased when $\mathbf{S 1}$ preceded $\mathbf{S} 2$, indicating that the fibres concerned had recovered from refractoriness and were beginning to show supernormality. During ischaemia, however, the response decreased rapidly in size so that whereas the control response to $\mathbf{S} 2$ alone had only fallen to $60 \%$ of the initial figure by the end of 12 minutes, the other had fallen from $118 \%$ to $22 \%$.

In the experiment shown in Fig. 13c the stimulus interval was $4.0 \mathrm{msec}$; at this interval the response to $\mathrm{S} 2$ was increased by $30 \%$ when $\mathrm{S} 2$ was preceded 


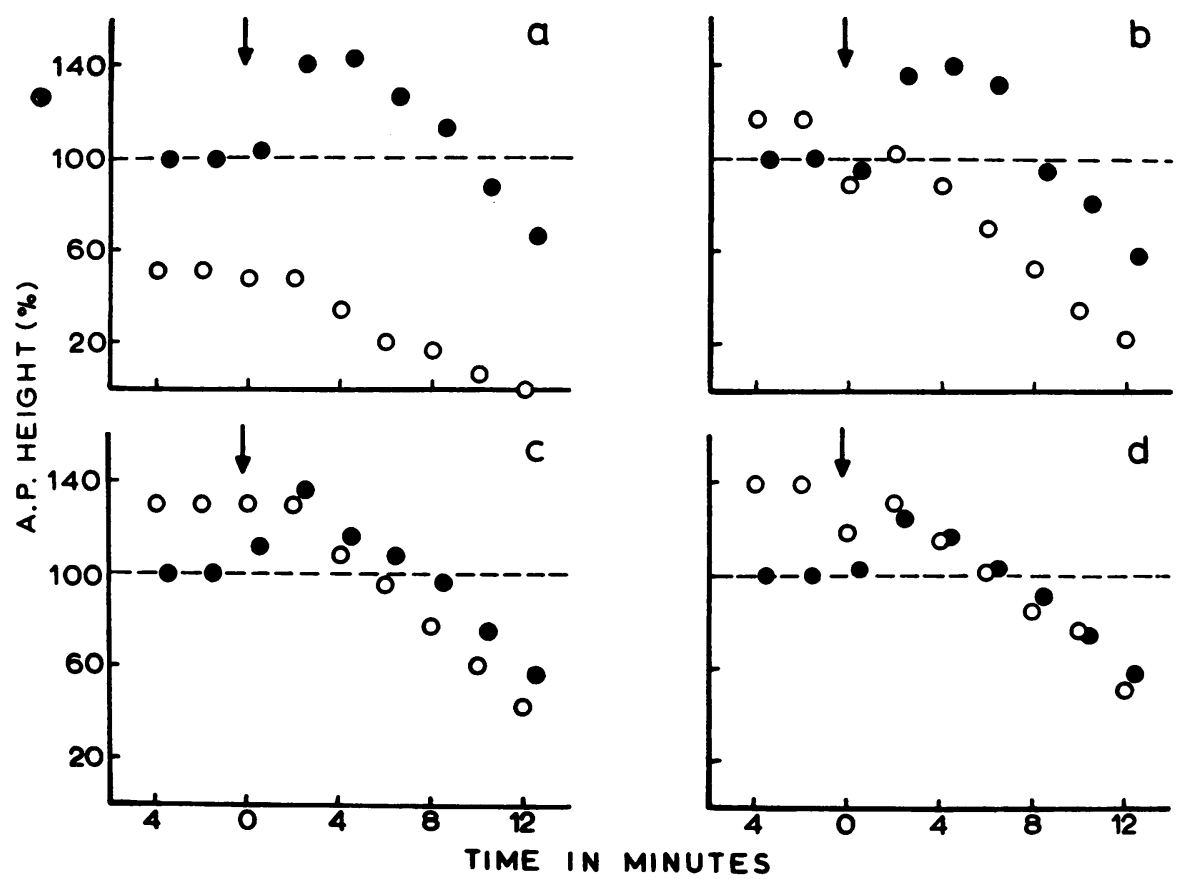

FIG. 13. Results of four experiments on subject R.W.G. Experimental arrangement as in Fig. 12. Open circles denote responses to week $S 2$ preceded by maximal $S 1$. Closed circles denote responses to $S 2$ alone. Cuff inflated at arrow. In each experiment amplitudes before and during ischaemia expressed as percentage of initial value of response to $S 2$ alone. Stimulus intervals, 2 msec. in (a), 3 msec. in (b), 4 msec. in (c), and 5 msec. in (d).

by $\mathrm{S1}$. As in Fig. 13b the effect of ischaemia was to reverse this, the response to $\mathbf{S} 2$ being substantially diminished when S1 was added. Thus the effect of ischaemia in this experiment was to increase the duration of the refractory period to more than 4.0 msec. In Fig. 12d the stimulus interval was $5.0 \mathrm{msec}$. and the effect of ischaemia was merely to eliminate supernormality.

Essentially similar results were obtained in the other subject tested, and it may be concluded that a brief period of ischaemia is sufficient to lengthen the duration of the refractory period by at least $50 \%$ and to abolish supernormal excitability.

\section{DISCUSSION}

When a nerve is stimulated by a single shock there follows a brief period during which it appears to be inexcitable to a second shock. For isolated spinal root and peripheral nerve preparations in the cat, Gasser and Grundfest (1936) were able to obtain a propagated response to the second stimulus of a pair with stimulus intervals of 0.41 to $0.44 \mathrm{msec}$. but this was only in the best preparations and in others a shock interval of $0.5 \mathrm{msec}$. was necessary. Using cat sciatic nerve in situ, Kiraly and Krnjević (1959) reported a mean figure of $0.52 \mathrm{msec}$. for seven estimations of the least interval. In our own experiments, responses to the second shock were seen at slightly longer intervals, namely 0.6 and $0.7 \mathrm{msec}$. in different subjects. This slightly longer interval in our human experiments may have been due to the fact that the strongest shocks which the subject could tolerate through the skin were not more than five or six times threshold for the nerve. In the animal experiments direct stimulation of the nerve allowed much higher ratios. Thus the period of inexcitability which we found might have been shorter if stronger shocks had been tolerated. However, it is doubtful whether a significant error has been introduced in this way; the curves in Fig. 3 show that the nerve threshold begins to rise very steeply when the stimulus interval is decreased to 0.6 or $0.7 \mathrm{msec}$. This makes it unlikely that the least interval at which a second response could be obtained would have been shortened appreciably even if stronger shocks to the nerve had been possible.

The slightly longer interval found in our experiments is more likely to have been due to the fact that the human median nerve contains smaller fibres 
with a lower conduction velocity than those studied in the animal experiments quoted above. The median nerve rarely contains fibres with a conduction velocity of more than $75 \mathrm{~m}$. $/ \mathrm{sec}$., whereas the cat peripheral nerve fibres studied by Gasser and Grundfest (1936) and by Kiraly and Krnjević (1959) had velocities ranging from 90 to $120 \mathrm{~m}$./sec. This difference may well account for the slightly longer shock interval required to produce a second propagated response in our human experiments.

In their study of the refractory period in the normal human ulnar nerve Krnjević et al. (1955) using pairs of 'maximal stimuli' were unable to record propagated responses to the second shock with intervals of less than $0.68 \mathrm{msec}$. on one subject and $0.96 \mathrm{msec}$. in the other. However, since no recovery curves are given, it is not certain from their paper whether these intervals could have been shortened if stimulus intensity had been increased.

It will be noted that in the foregoing discussion we have avoided using the term 'absolute refractory period'. The use of this term has been criticized by Tasaki (1953), who pointed out that with very short stimulus intervals it was possible to obtain a local response to the second stimulus which was so weak that it failed to propagate, the least interval for excitation being significantly shorter than that necessary to produce a second propagated response; thus the term 'absolute refractory period' should be applied to the first of these intervals rather than to the second.

The recovery of normal excitability at about $3 \mathrm{msec}$. in our experiments, followed by a supernormal period lasting for a further 5 to $15 \mathrm{msec}$., closely resembles the excitability changes reported for mammalian nerve by Gasser and Grundfest (1936) and by Graham and Lorente de Nó (1938). The constant presence of a supernormal period in human nerve (also noted by Brown, 1960) is of some interest as there was considerable discussion among earlier workers on the extent to which supernormality might depend upon manipulation of exposed or isolated nerve during animal experiments. Whereas in Gasser and Grundfest's saphenous nerve preparation in the cat supernormality was a constant finding during the recovery of excitability, Graham and Lorente de Nó, who used mainly rabbit sciatic nerve, remarked that recovery without supernormality was found "when the preparation was made with the smallest amount of manipulation and delay, and the nerve had been submitted to but little stimulation; recovery with supernormality was not found until after more experimentation'. In our own experiments on human nerve supernormality was sometimes abolished if electrodes were strapped in place so tightly that they produced a pressure block of the nerve. Provided, however, that this was avoided supernormal excitability appeared to be a constant and reproducible component of the normal recovery cycle as described by Gasser and Grundfest.

With regard to the effect of refractoriness on conduction velocity, our results are in full agreement with those of earlier workers ( $c f .$, Gasser and Erlanger, 1925). It is clear that an action potential is propagated with a reduced velocity in the relative refractory period; the effect of this is to cause the second of two impulses to lag increasingly behind the first until the end of the refractory period is reached, at which point the velocity of the second impulse will have recovered to equal that of the first. This must have the effect of limiting the frequency of a train of impulses travelling over a long length of nerve, regardless of the frequency of initiation.

It is sometimes assumed that the capacity of nerve fibres to carry trains of impulses at high frequencies is greatly in excess of that required during physiological activity. In recent work on animals, however, discharge frequencies of afferent fibres in response to end-organ stimulation have been reported which imply conduction in partiallo refractory nerve. For example, discharge fre quencies of 400 to 800 per second in single afferen\& fibres of the cat were described by Hunt and McIntyre (1960a and b) and by Hunt (1961). In such cases the maximal frequency recorded would presumably be limited by the refractory period of the nerve fibre and by the conduction distance.

In the small number of experiments carried out by Hensel and Boman (1960) on the human radial nerve the highest discharge frequency recorded in single mechanoreceptor fibres in response to skin stimulation was 330 per second; this suggests that in man also the peak frequency of physiological firing might on occasion be limited by the refractory period of the nerve fibre.

Since physiological activity can involve discharge intervals close to the refractory period of the nerve fibre, one might expect significant disturbances of function if the refractory period were prolonged by disease. We have not as yet studied refractoriness in pathological nerve but the changes which we have observed during experimental ischaemia emphasize the need for such a study.

\section{SUMMARY}

The excitability changes which follow a propagated action potential in the median nerve were studied in four healthy subjects.

After a single supramaximal shock to the nerve at the wrist the least interval at which a second pro- 
pagated response could be obtained ranged from 0.6 to $0.7 \mathrm{msec}$. in different subjects. Recovery of normal excitability was complete by 2.5 to $3.5 \mathrm{msec}$. and was followed by a period of supernormal excitability lasting for a further 5 to $15 \mathrm{msec}$.

The conduction velocity of an action potential travelling in the relative refractory period was reduced. When two stimuli were delivered at a short interval, normal velocity was not recovered by the second action potential of the pair within $30 \mathrm{~cm}$. of the site of stimulation.

The effect of a 12-minute period of nerve ischaemia was to increase the duration of the refractory period by at least $50 \%$ and to abolish supernormality.

Grants towards the cost of the apparatus were made by the Medical Research Council and the Mary Kinross Charitable Trust, and we also gratefully acknowledge the provision of facilities by the Clinical Research Committee of the Middlesex Hospital.

\section{REFERENCES}

Adrian, E. D., and Lucas, K. (1912). J. Physiol. (Lond.), 44, 68.

Brown, J. E. (1960). M.Sc.Thesis. Massachusetts Institute of Techno$\log y$.

Dawson, G. D., and Scott, J. W. (1949). J. Neurol. Neurosurg. Psychiat., $12,259$.

Forbes, A., Ray, L. H., and Griffith, F. R. (1923). Amer. J. Physiol., 66, 553.

Gasser, H. S., and Erlanger, J. (1925). Ibid., 73, 613. , and Grundfest, H. (1936). Ibid., 117, 113 .

Gilliatt, R. W., and Willison, R. G. (1962). J. Physiol. (Lond.), 161, $29 \mathrm{P}$.

Graham, H. T., and Lorente de Nó, R. (1938). Amer. J. Physiol., 123, 326.

Hensel, H., and Boman, K. K. A. (1960). J. Neurophysiol., 23, 564.

Hunt, C. C. (1961). J. Physiol. (Lond.), 155, 175.

$\longrightarrow$, and McIntyre, A. K. (1960a). Ibid., 153, 74

- - (1960b). Ibid., 153, 88.

Kiraly, J. K., and Krnjević, K. (1959). Quart. J. exp. Physiol., 44, 244.

Krnjevic, K., Kilpatrick, R., and Aungle, P. G. (1955). Ibid., 40, 203.

Kugelberg, E. (1944). Acta physiol. scand., 8, suppl., 24.

Tasaki, I. (1953). Nervous Transmission. Thomas, Springfield, Illinois.

Wagman, I. H., and Flick, E. W. (1951). Amer. J. Physiol., 167, 834. 